\title{
Adaptive Thermal Comfort in Japanese Houses during the Summer Season: Behavioral Adaptation and the Effect of Humidity
}

\section{Hom B. Rijal ${ }^{1, *}$, Michael Humphreys ${ }^{2}$ and Fergus Nicol ${ }^{2}$}

1 Department of Restoration Ecology and Built Environment, Faculty of Environmental Studies, Tokyo City University, 3-3-1 Ushikubo-nishi, Tsuzuki-ku, Yokohama 224-8551, Japan

2 School of Architecture, Faculty of Technology, Design and Environment, Oxford Brookes University, Headington Campus, Gipsy Lane, Oxford OX3 0BP, UK;

E-Mails: mahumphreys@brookes.ac.uk (M.H.); jfnicol@brookes.ac.uk (F.N.)

* Author to whom correspondence should be addressed; E-Mail: rijal@tcu.ac.jp; Tel.: +81-45-910-2616; Fax: +81-45-910-2605.

Academic Editor: Tri Harso Karyono

Received: 3 August 2015 / Accepted: 29 August 2015 / Published: 11 September 2015

\begin{abstract}
In order to clarify effect of humidity on the room temperatures reported to be comfortable, an occupant thermal comfort and behavior survey was conducted for five summers in the living rooms and bedrooms of residences in the Kanto region of Japan. We have collected 13,525 thermal comfort votes from over 239 residents of 120 homes, together with corresponding measurements of room temperature and humidity of the air. The residents were generally well-satisfied with the thermal environment of their houses, with or without the use of air-conditioning, and thus were well-adapted to their thermal conditions. The humidity was found to have very little direct effect on the comfort temperature. However, the comfort temperature was strongly related to the reported skin moisture. Behavioral adaptation such as window opening and fan use increase air movement and improve thermal comfort.
\end{abstract}

Keywords: dwellings; summertime; humidity; skin moisture; comfort temperature; occupant behavior 


\section{Introduction}

Thermal comfort is one of the most important factors in creating more comfortable homes. Investigating and establishing the comfort temperature of the residents can suggest customary temperatures in the house, so as to minimize excessive energy use and save the overall energy costs of the household. There have already been a number of research projects about the comfort temperature of houses in Japan [1,2], China [3], Singapore [4], Malaysia [5], Indonesia [6], Nepal [7], India [8], Pakistan [9,10], Iran [11] and UK [12]. However there are limitations in the research to date with some studies conducted over short time periods, and some based on small samples. The Japanese summer is especially hot and humid, and the Japanese government recommends the indoor temperature setting of $28^{\circ} \mathrm{C}$, but the recommendation lacks supporting evidence from any field survey. Thus we need to investigate comfort temperatures and the effect of humidity on the occupants of dwellings.

American Society of Heating Refrigeration and Air-Conditioning Engineers (ASHRAE) [13] and Comité Européen de Normalisation (CEN) [14] have proposed adaptive models for naturally ventilated and free running building design. Japanese data is not included in either of these adaptive models. Occupant behavior in the office and at home is different, and thus the existing adaptive models may not be applicable to Japanese homes. So we need to construct an adaptive model using thermal comfort survey-data from Japanese dwellings.

In hot and humid conditions air movement is an important factor in determining the indoor comfort temperature [15]. Behavioral adaptation such as window opening and fan use can increase the air movement for adaptive thermal comfort. Occupant behaviors are important for explaining the mechanism of the adaptive model. However, how people behaviorally adapt to the hot and humid season is not yet fully understood [16,17].

In order to clarify the comfort temperature and investigate behavioral adaptation in Japanese houses we conducted a thermal comfort survey and an occupant behavior survey in the living rooms and bedrooms of 120 houses during the hot and humid season in the Kanto region of Japan.

\section{Field Investigation}

The indoor air temperature, the globe temperature and the relative humidity were measured in the living rooms and bedrooms, avoiding direct sunlight, at ten minute intervals using a data logger (Figure 1, Table 1). Outdoor air temperature and relative humidity were obtained from the nearest meteorological station. The number of subjects was 116 males and 123 females (Table 2). The mean ages and standard deviations of male and female subjects were $41.5 \pm 18.0$ years and $43.6 \pm 14.8$ years. The thermal comfort survey was conducted several times a day using a seven-point thermal sensation scale and a five-point thermal preference scale (Table 3). Occupant behavior in the living room was recorded in binary form several times a day $(0=$ window closed, cooling off, or fan off; 1 = window open, cooling on, or fan on). The surveys were conducted from 2010 to 2014 [18], and only summer (June to August) data are presented in this paper; 13,525 sets of subjective responses with their accompanying physical measurements (Table 2). These data were analyzed using Statistical Package for Social Science (SPSS) version 19. 


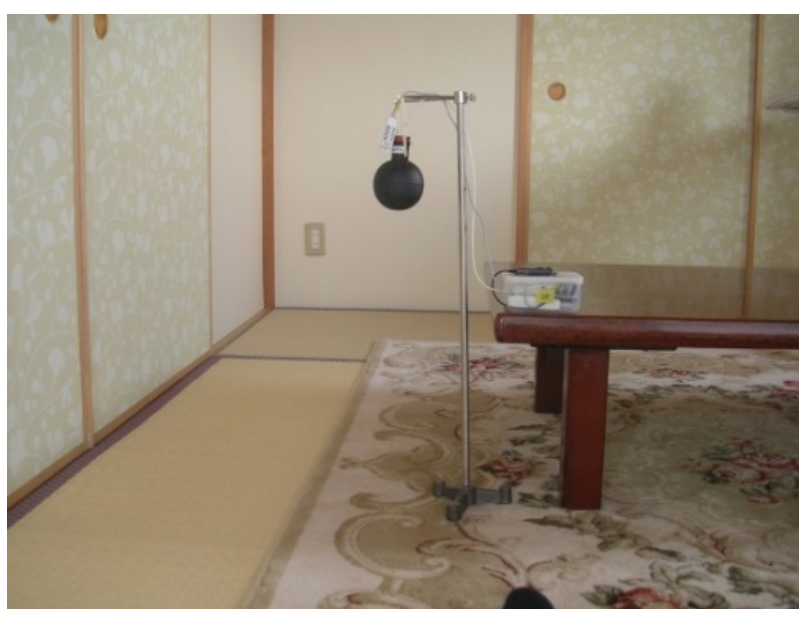

Figure 1. Measurement of indoor air temperature, globe temperature and relative humidity.

Table 1. Details of the instruments used for the environmental measurement.

\begin{tabular}{cccc}
\hline Parameter Measured & Trade Name & Range & Accuracy \\
\hline \multirow{2}{*}{ Air temperature, Humidity } & TR-74Ui & 0 to $55^{\circ} \mathrm{C}, 10 \%$ to $95 \% \mathrm{RH}$ & $\pm 0.5{ }^{\circ} \mathrm{C}, \pm 5 \%$ \\
& RTR-53A & 0 to $55^{\circ} \mathrm{C}, 10 \%$ to $95 \% \mathrm{RH}$ & $\pm 0.3{ }^{\circ} \mathrm{C}, \pm 5 \%$ \\
\hline \multirow{2}{*}{ Globe temperature } & Tr-52i & -60 to $155^{\circ} \mathrm{C}$ & $\pm 0.3{ }^{\circ} \mathrm{C}$ \\
& SIBATA $080340-75$ & Black painted $75 \mathrm{~mm}$ diameter globe \\
\hline
\end{tabular}

Table 2. Description of survey for summer (2010 to 2014).

\begin{tabular}{cccccccccc}
\hline \multirow{2}{*}{ Survey } & \multirow{2}{*}{$\begin{array}{c}\text { Surveyed } \\
\text { Room }\end{array}$} & Measured & Number of & \multicolumn{2}{c}{ Number of Subjects } & \multicolumn{3}{c}{ Number of Votes } \\
\cline { 5 - 9 } & Variables * & Houses & Male & Female & Total & Living Room & Bedroom \\
\hline 1 & Living, Bed & $T_{i}, R H_{i}$ & 11 & 16 & 14 & 30 & 1600 & 1194 \\
2 & Living & $T_{i}, R H_{i}$ & 59 & 52 & 57 & 109 & 2316 & - \\
3 & Living, Bed & $T_{i}, R H_{i}, T_{g}$ & 10 & 9 & 11 & 20 & 305 & 586 \\
4 & Living, Bed & $T_{i}, R H_{i}, T_{g}$ & 30 & 26 & 28 & 54 & 3674 & 1939 \\
5 & Living, Bed & $T_{i}, R H_{i}, T_{g}$ & 10 & 13 & 13 & 26 & 918 & 993 \\
\hline Total & - & - & 120 & 116 & 123 & 239 & 8813 & 4712 \\
\hline
\end{tabular}

Notes: $T_{i}$ : Indoor air temperature $\left({ }^{\circ} \mathrm{C}\right), R H_{i}$ : Indoor relative humidity $(\%), T_{g}$ : Indoor globe temperature $\left({ }^{\circ} \mathrm{C}\right)$, ${ }^{*} T_{g}$ is measured only in the living room.

Table 3. Questionnaires for thermal comfort survey.

\begin{tabular}{|c|c|c|c|c|}
\hline & SHASE Scale & ASHRAE Scale & Thermal Preference & Skin Moisture \\
\hline No. & $\begin{array}{l}\text { Now, how do you feel the } \\
\text { air temperature? }\end{array}$ & $\begin{array}{l}\text { Now, how do you feel the air } \\
\text { temperature? }\end{array}$ & $\begin{array}{l}\text { Now, how do you prefer } \\
\text { the air temperature? }\end{array}$ & $\begin{array}{l}\text { How do you feel skin } \\
\text { moisture at this time? }\end{array}$ \\
\hline 1 & Very cold & Cold & Much warmer & None \\
\hline 2 & Cold & Cool & A bit warmer & Slightly \\
\hline 3 & Slightly cold & Slightly cool & No change & Moderate \\
\hline 4 & Neutral (neither cold nor hot) & Neutral (neither cool nor warm) & A bit cooler & Profuse \\
\hline 5 & Slightly hot & Slightly warm & Much cooler & - \\
\hline 6 & Hot & Warm & - & - \\
\hline 7 & Very hot & Hot & - & - \\
\hline
\end{tabular}


Although the ASHRAE scale is frequently used to evaluate the thermal sensation, the words "warm" or "cool" imply comfort in Japanese, and thus The Society of Heating, Air-Conditioning and Sanitary Engineers of Japan (SHASE) scale is also used to evaluate the thermal sensation. To avoid the possible misunderstanding of "neutral" in the thermal sensation scale, it is explained as "neutral (neither cold nor hot)" (SHASE scale) or "neutral (neither cool nor warm)" (ASHRAE scale). It is also said that the optimum thermal sensation occurs on the cooler side of "neutral" in summer and on the warmer side in winter $[1,19]$.

\section{Results and Discussion}

\subsection{The Modes}

The data were divided into two groups: the free running (FR) mode and cooling by air conditioning mode (CL) [20]. If cooling was being used at the time of completion of the survey the data were classified as being in the CL mode. All other data were classified as being in the FR mode. Whether the cooling was on or off was noted by the subjects whenever they gave their subjective responses, and the classification of the mode of operation relies on the information the subjects provided.

\subsection{Distribution of Temperature and Humidity}

The monthly mean indoor and globe temperature is very similar in FR and CL mode (Figure 2a), and the correlation coefficient is similarly high in both modes (Table 4). In FR mode, indoor temperatures are higher than the outdoor air temperature. However, in CL mode, the indoor temperatures are lower than the outdoor air temperature, except in June. The Japanese government recommends the indoor temperature settings of $28^{\circ} \mathrm{C}$ in summer. The results showed that the mean indoor temperature setting in CL mode was similar to the recommendation. The mean indoor relative humidity and absolute humidity are lower than the outdoor relative humidities (Figure 2b,c). Due to the mechanical cooling, the mean indoor relative humidity or correlation coefficient of the CL mode is lower than the FR mode. The results showed that the relative humidity in FR mode is slightly higher than the standard: $60 \%$. To predict the indoor air or globe temperature, regression analysis was conducted. The equations are given below.

FR mode:

$$
\begin{aligned}
& T_{i}=0.499 T_{o}+15.228\left(n=8280, R^{2}=0.59, \text { S.E. }=0.005, p<0.001\right) \\
& T_{g}=0.480 T_{o}+15.507\left(n=2785, R^{2}=0.58, \text { S.E. }=0.008, p<0.001\right)
\end{aligned}
$$

CL mode:

$$
\begin{gathered}
T_{i}=0.151 T_{o}+23.239\left(n=4860, R^{2}=0.04, \text { S.E } .=0.10, p<0.001\right) \\
T_{g}=0.200 T_{o}+22.115\left(n=2109, R^{2}=0.10, \text { S.E. }=0.013, p<0.001\right)
\end{gathered}
$$

$T_{i}$ : indoor air temperature $\left({ }^{\circ} \mathrm{C}\right) ; T_{g}$ : globe temperature $\left({ }^{\circ} \mathrm{C}\right) ; T_{o}$ : outdoor air temperature $\left({ }^{\circ} \mathrm{C}\right) ; n$ : number in sample; $R^{2}$ : coefficient of determination; S.E.: standard error of the regression coefficient; $p$ : significance level of regression coefficient. The correlation between the indoor and outdoor temperature of the FR mode is higher than the CL mode (Figure 3). 
(a) Temperature (Summer)

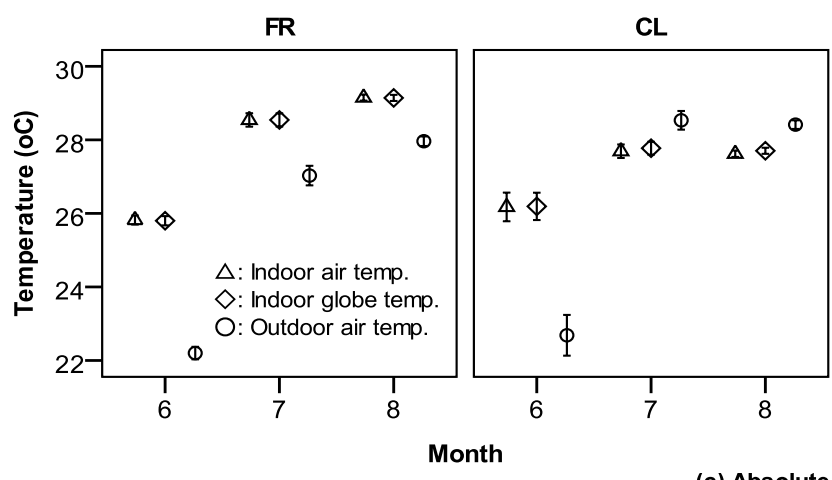

(c) Absolute humidity (Summer)

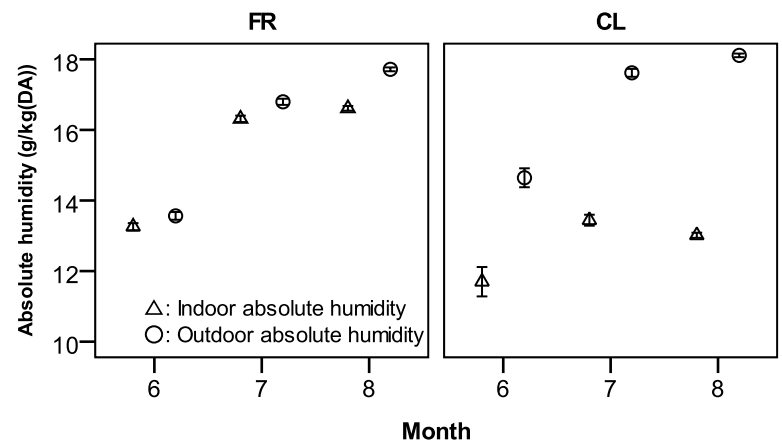

(b) Relative humidity (Summer)

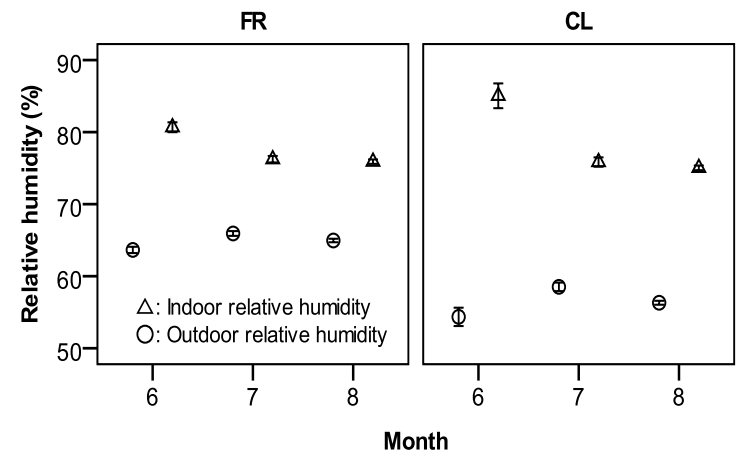

Month

Figure 2. Monthly mean values with $95 \%$ confidence interval (Error bar): (a) temperature; (b) relative humidity; (c) absolute humidity.

Table 4. The correlation coefficient.

\begin{tabular}{cccccc}
\hline Mode & Items & $\boldsymbol{T}_{\boldsymbol{i}}: \boldsymbol{T}_{\boldsymbol{o}}$ & $\boldsymbol{T}_{\mathrm{g}}: \boldsymbol{T}_{\boldsymbol{o}}$ & $\boldsymbol{T}_{\boldsymbol{i}}: \boldsymbol{T}_{\boldsymbol{g}}$ & $\boldsymbol{R H}_{\boldsymbol{i}}: \boldsymbol{R} \boldsymbol{H}_{\boldsymbol{o}}$ \\
\hline \multirow{2}{*}{ FR } & $r$ & 0.77 & 0.76 & 0.99 & 0.45 \\
& $N$ & 8280 & 2785 & 2751 & 7924 \\
\hline \multirow{2}{*}{ CL } & $r$ & 0.20 & 0.31 & 0.91 & 0.18 \\
& $N$ & 4860 & 2109 & 1911 & 4856 \\
\hline
\end{tabular}

Note: $T_{i}$ : indoor air temperature $\left({ }^{\circ} \mathrm{C}\right) ; T_{g}$ : indoor globe temperature $\left({ }^{\circ} \mathrm{C}\right) ; T_{o}$ : outdoor air temperature $\left({ }^{\circ} \mathrm{C}\right) ; R H_{\mathrm{i}}$ : indoor relative humidity $(\%) ; R H_{o}$ : outdoor relative humidity $(\%) ; r$ : correlation coefficient; $N$ : number in sample; correlation coefficient is significant at the 0.01 level (2-tailed).

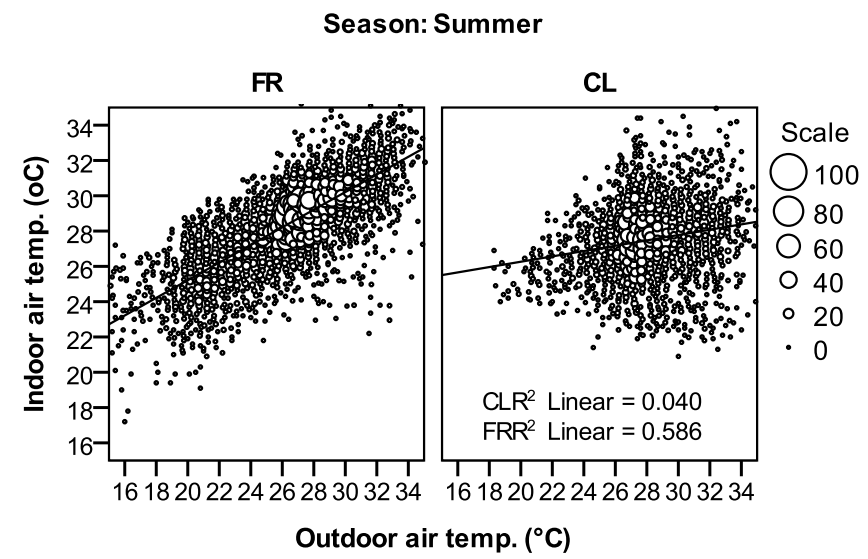

Figure 3. Relation between the indoor and outdoor air temperature when voted (all raw data). 


\subsection{Thermal Comfort}

\subsubsection{Comparison of the Scales}

We wished to compare the performance of the SHASE scale and the ASHRAE scale. Table 5 shows the correlation of the thermal sensation and thermal preference with the room temperature. The SHASE scale is more strongly correlated with the thermal preference than is the ASHRAE scale. Also the SHASE scale correlates more strongly with the indoor air temperature and globe temperature. We have therefore chosen to use the SHASE scale rather than the ASHRAE scale for the analysis of the survey data.

Table 5. Correlation coefficient with ASHRAE and SHASE scales.

\begin{tabular}{cccccccc}
\hline \multirow{2}{*}{ Mode } & \multirow{2}{*}{ Items } & \multicolumn{3}{c}{ ASHRAE } & \multicolumn{3}{c}{ SHASE } \\
\cline { 3 - 8 } & & $\boldsymbol{T P}$ & $\boldsymbol{T}_{\boldsymbol{i}}$ & $\boldsymbol{T}_{\mathbf{g}}$ & $\boldsymbol{T P}$ & $\boldsymbol{T}_{\boldsymbol{i}}$ & $\boldsymbol{T}_{\mathbf{g}}$ \\
\hline \multirow{2}{*}{ FR } & $r$ & 0.74 & 0.47 & 0.42 & 0.82 & 0.49 & 0.47 \\
& $N$ & 5540 & 5451 & 2789 & 7526 & 8282 & 2788 \\
\hline \multirow{2}{*}{ CL } & $r$ & 0.70 & 0.26 & 0.26 & 0.81 & 0.28 & 0.31 \\
& $N$ & 3859 & 3588 & 2109 & 4800 & 4857 & 2109 \\
\hline
\end{tabular}

Note: $T P$ : thermal preference; $T_{i}$ : indoor air temperature $\left({ }^{\circ} \mathrm{C}\right) ; T_{\mathrm{g}}$ : globe temperature $\left({ }^{\circ} \mathrm{C}\right) ; p<0.001$; $p$ : significance level; $r$ : correlation coefficient; $N$ : number of sample.

\subsubsection{Distribution of Thermal Sensation}

Table 6 shows the percentages of the thermal sensations in each scale category for the FR and CL modes. The mean thermal sensation was 4.7 in FR mode, 4.2 in CL mode. Even when residents used the cooling, they sometimes felt "hot". The proportion of people voting in the thermal comfort zone (votes 3, 4 or 5) in the FR and CL modes is $83 \%$ and $94 \%$ (Table 6). It can be said that residents were generally satisfied with the thermal environment of their houses. This may be because the residents are well-adapted to the local climate and culture.

Table 6. Percentage of thermal sensation on the SHASE scale in FR and CL modes.

\begin{tabular}{cccccccccc}
\hline \multirow{2}{*}{ Mode } & Items & $\mathbf{1}$ & $\mathbf{2}$ & $\mathbf{3}$ & $\mathbf{4}$ & $\mathbf{5}$ & $\mathbf{6}$ & $\mathbf{7}$ & \multirow{2}{*}{ Total } \\
\cline { 3 - 9 } & $N$ & 2 & 8 & 210 & 4044 & 2701 & 1,173 & 257 & 8395 \\
\multirow{2}{*}{ FR } & $P(\%)$ & 0.0 & 0.1 & 2.5 & 48.2 & 32.2 & 14.0 & 3.1 & 100 \\
\hline \multirow{2}{*}{$\mathrm{CL}$} & $N$ & 6 & 30 & 368 & 3487 & 964 & 226 & 49 & 5130 \\
& $P(\%)$ & 0.1 & 0.6 & 7.2 & 68.0 & 18.8 & 4.4 & 1.0 & 100 \\
\hline \multicolumn{8}{c}{ Note: $N$ : number of sample; $P$ : percentage. }
\end{tabular}

To locate the thermal comfort zone, Probit regression analysis [21] was conducted for the thermal sensation vote (TSV) categories and the temperature, for FR and CL modes. The analysis method is Ordinal regression using Probit as the link function and the temperature as the covariate.

The results of the Probit analysis is shown in Table 7. The temperature corresponding to the median response (Probit $=0$ ) is calculated by dividing the constant by regression coefficient. For example, the 
mean temperature of the first equation will be $4.151 / 0.288=14.4{ }^{\circ} \mathrm{C}$ (Table 7). The inverse of the Probit regression coefficient is the standard deviation of the cumulative Normal distribution. For example, the standard deviation of air temperature of the FR mode will be $1 / 0.288=3.472{ }^{\circ} \mathrm{C}$ (Table 7). These calculations are fully given in the Table 7. Transforming the Probits using the following function into proportions gives the curve of Figure $4 \mathrm{a}-\mathrm{d}$. The vertical axis is the proportion of votes.

$$
\text { Probability }=\text { CDF.NORMAL (quant, mean, S.D.) }
$$

where "CDF.NORMAL" is the Cumulative Distribution Function for the normal distribution, "quant" is the indoor air temperature $\left({ }^{\circ} \mathrm{C}\right)$ or globe temperature $\left({ }^{\circ} \mathrm{C}\right)$; the "mean" and "S.D." are given in the Table 7.

(a) FR

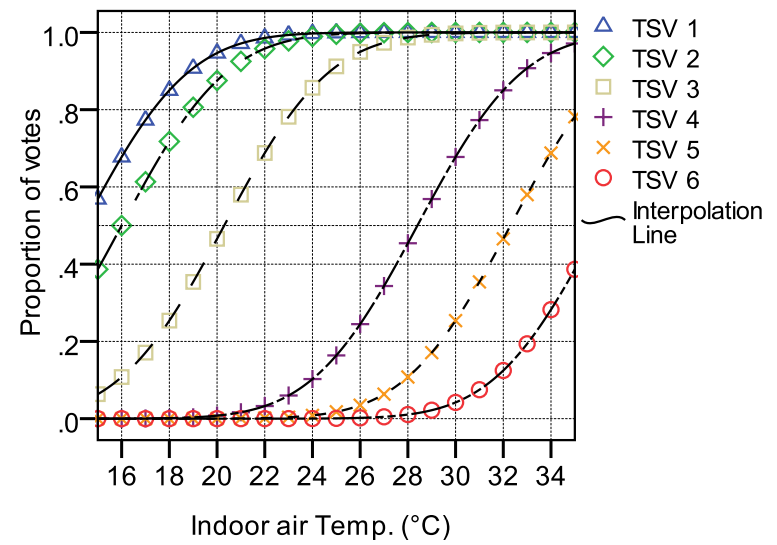

(c) $\mathrm{CL}$

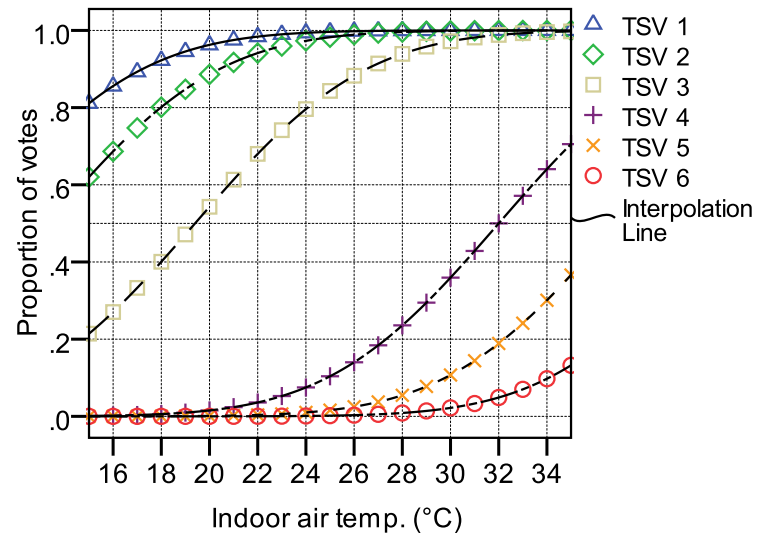

(e)

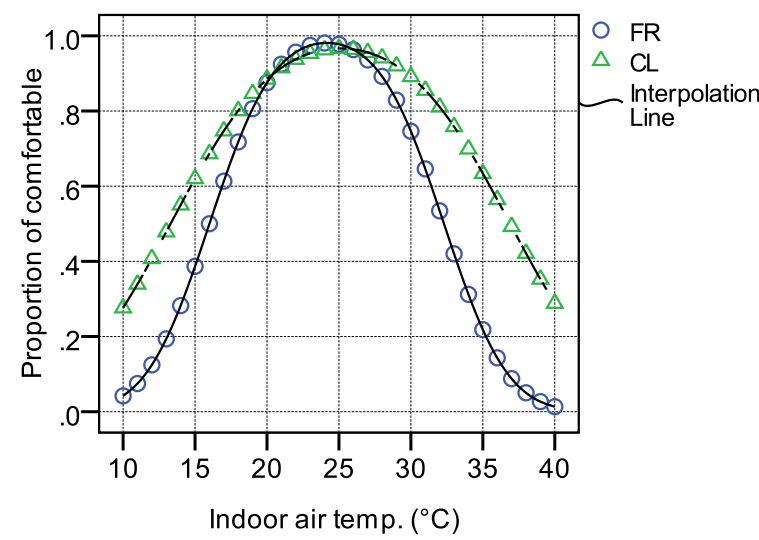

(b) FR

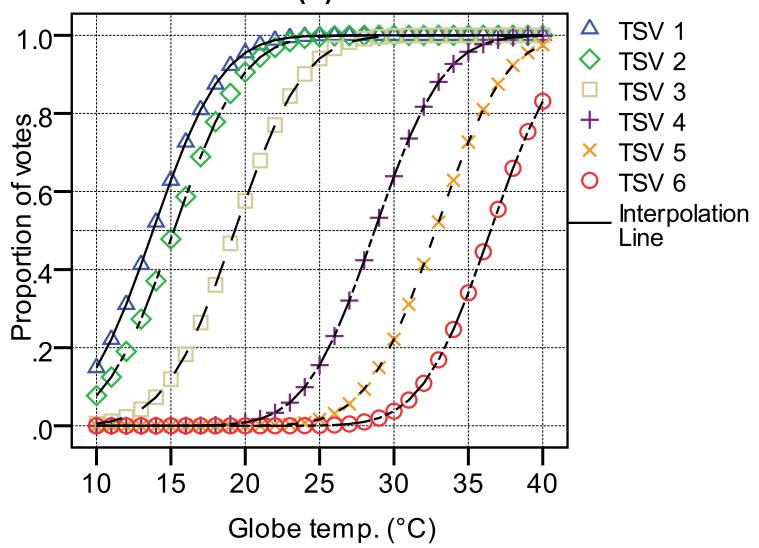

(d) $\mathrm{CL}$

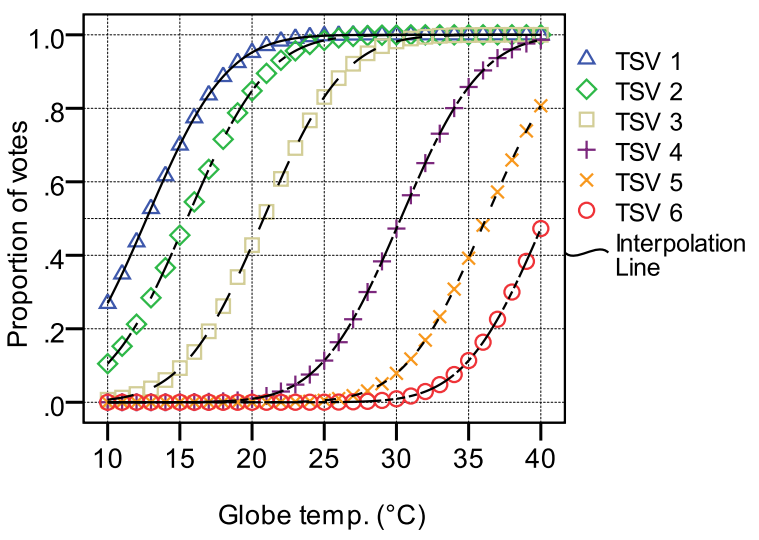

(f)

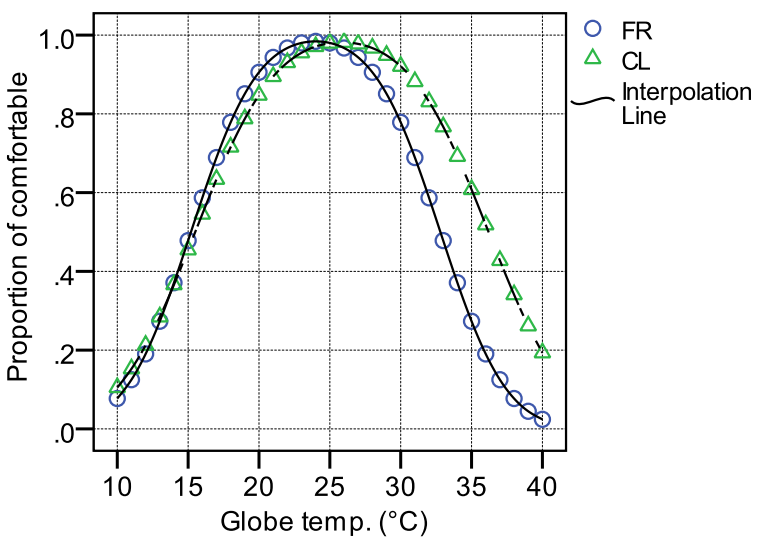

Figure 4. Proportion of thermal sensation vote (TSV) or comfortable (TSV 3, 4 or 5) for temperatures: (a) and (b) FR mode; (c) and (d) CL mode; (e) and (f) FR and CL modes. 
Table 7. Percentage of thermal sensation in FR and CL modes.

\begin{tabular}{|c|c|c|c|c|c|c|c|c|c|c|c|c|}
\hline \multirow{2}{*}{ Mode } & \multicolumn{6}{|c|}{ Indoor Air Temperature $T_{i}\left({ }^{\circ} \mathrm{C}\right)$} & \multicolumn{6}{|c|}{ Globe Temperature $T_{\mathrm{g}}\left({ }^{\circ} \mathrm{C}\right)$} \\
\hline & Equation * & Mean & S.D. & $N$ & $R^{2}$ & S.E. & Equation * & Mean & S.D. & $N$ & $R^{2}$ & S.E. \\
\hline \multirow{6}{*}{ FR } & $P_{(\leq 1)}=0.288 T_{i}-4.151$ & 14.4 & \multirow{6}{*}{3.472} & \multirow{6}{*}{8282} & \multirow{6}{*}{0.25} & \multirow{6}{*}{0.006} & $P_{(\leq 1)}=0.274 T_{g}-3.784$ & 13.8 & \multirow{6}{*}{3.650} & \multirow{6}{*}{2788} & \multirow{6}{*}{0.23} & \multirow{6}{*}{0.011} \\
\hline & $P_{(\leq 2)}=0.288 T_{i}-4.602$ & 16.0 & & & & & $P_{(\leq 2)}=0.274 T_{g}-4.156$ & 15.2 & & & & \\
\hline & $P_{(\leq 3)}=0.288 T_{i}-5.843$ & 20.3 & & & & & $P_{(\leq 3)}=0.274 T_{g}-5.282$ & 19.3 & & & & \\
\hline & $P_{(\leq 4)}=0.288 T_{i}-8.186$ & 28.4 & & & & & $P_{(\leq 4)}=0.274 T_{g}-7.851$ & 28.7 & & & & \\
\hline & $P_{(\leq 5)}=0.288 T_{i}-9.299$ & 32.3 & & & & & $P_{(\leq 5)}=0.274 T_{g}-8.999$ & 32.8 & & & & \\
\hline & $P_{(\leq 6)}=0.288 T_{i}-10.376$ & 36.0 & & & & & $P_{(\leq 6)}=0.274 T_{g}-10.002$ & 36.5 & & & & \\
\hline \multirow{6}{*}{$\mathrm{CL}$} & $P_{(\leq 1)}=0.180 T_{i}-1.821$ & 10.1 & \multirow{6}{*}{5.556} & \multirow{6}{*}{4857} & \multirow{6}{*}{0.08} & \multirow{6}{*}{0.009} & $P_{(\leq 1)}=0.228 T_{g}-2.895$ & 12.7 & \multirow{6}{*}{4.386} & \multirow{6}{*}{2109} & \multirow{6}{*}{0.09} & \multirow{6}{*}{0.016} \\
\hline & $P_{(\leq 2)}=0.180 T_{i}-2.394$ & 13.3 & & & & & $P_{(\leq 2)}=0.228 T_{g}-3.538$ & 15.5 & & & & \\
\hline & $P_{(\leq 3)}=0.180 T_{i}-3.483$ & 19.4 & & & & & $P_{(\leq 3)}=0.228 T_{g}-4.750$ & 20.8 & & & & \\
\hline & $P_{(\leq 4)}=0.180 T_{i}-5.765$ & 32.0 & & & & & $P_{(\leq 4)}=0.228 T_{g}-6.917$ & 30.3 & & & & \\
\hline & $P_{(\leq 5)}=0.180 T_{i}-6.648$ & 36.9 & & & & & $P_{(\leq 5)}=0.228 T_{g}-8.244$ & 36.2 & & & & \\
\hline & $P_{(\leq 6)}=0.180 T_{i}-7.422$ & 41.2 & & & & & $P_{(\leq 6)}=0.228 T_{g}-9.190$ & 40.3 & & & & \\
\hline
\end{tabular}

Note: $P_{(\leq 1)}$ is the probit of proportion of the votes that are 1 and less, $P_{(\leq 2)}$ is the probit of the proportion that are 2 and less, and so on; S.D.: standard deviation of the cumulative normal distribution; $N$ : number of sample; $R^{2}$ : cox and snell $R^{2}$; S.E.: standard error of the regression coefficient; * regression coefficient is significant $(p<0.001)$. 
The highest line is for category 1 (very cold) and so on successively. Thus, it can be seen that the temperature for thermal neutrality (a probability of 0.5 ) is around 24 to $26{ }^{\circ} \mathrm{C}$.

Reckoning the three central categories as representing thermal comfort, and transforming the Probits into proportions gives the bell-curve of Figure 4e,f. The result is remarkable in two respects. The proportion of people comfortable at the optimum is very high, only just less that $100 \%$, and the range over which $80 \%$ are comfortable is wide-from around 18 to $32{ }^{\circ} \mathrm{C}$. This is presumably because people in their own homes are free to clothe themselves according to the room temperature, without the constraints that are apt to apply at the office.

\subsection{The Comfort Temperature}

To predict the comfort temperature, regression analysis of the thermal sensation and indoor air or globe temperature was conducted (Figure 5). The following regression equations are obtained.

FR mode:

$$
\begin{aligned}
& C=0.187 T_{i}-0.637\left(n=8282, R^{2}=0.24, \text { S.E. }=0.004, p<0.001\right) \\
& C=0.164 T_{g}-0.004\left(n=2788, R^{2}=0.22, \text { S.E. }=0.006, p<0.001\right)
\end{aligned}
$$

CL mode:

$$
\begin{aligned}
& C=0.106 T_{i}+1.294\left(n=4857, R^{2}=0.08, \text { S.E. }=0.005, p<0.001\right) \\
& C=0.124 T_{g}+0.829\left(n=2109, R^{2}=0.09, \text { S.E. }=0.008, p<0.001\right)
\end{aligned}
$$

$C$ is the thermal sensation vote.

(a) Season: Summer

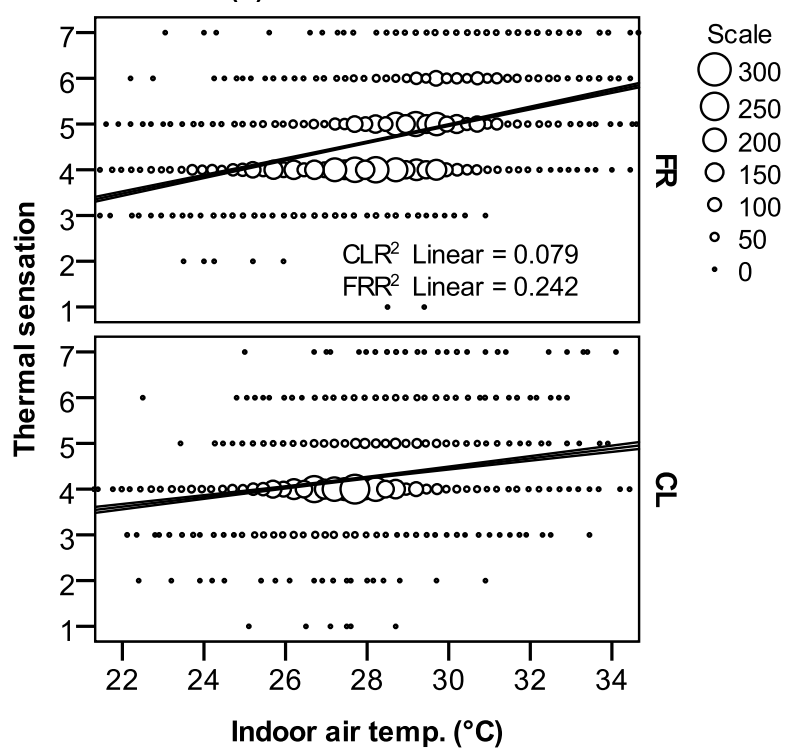

(b) Season: Summer

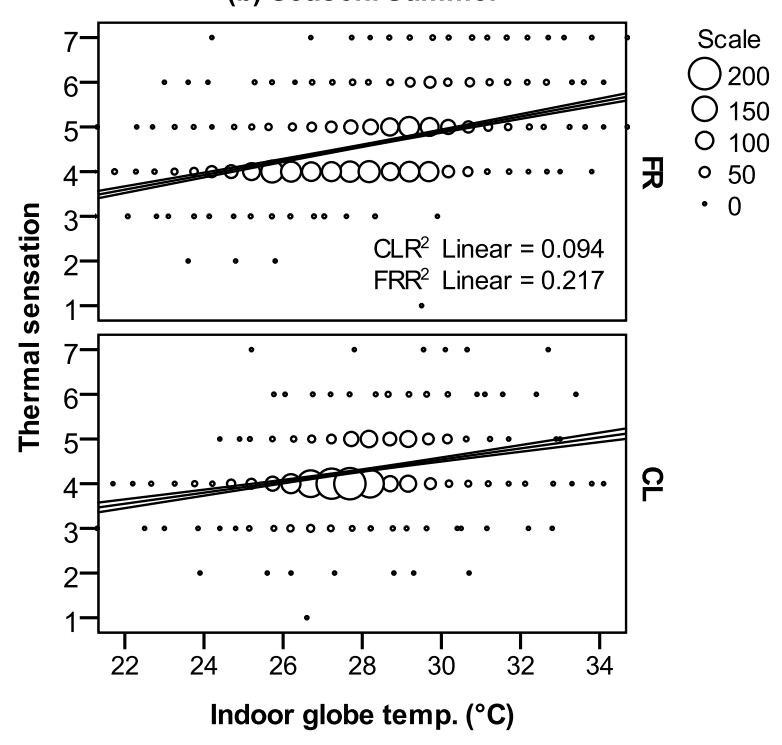

Figure 5. Relation between thermal sensation and the temperature: (a) Thermal sensation and indoor air temperature; (b) Thermal sensation and indoor globe temperature. 
The regression coefficient for the FR mode is higher than that of the CL. When the indoor or globe comfort temperature is predicted by substituting 4 (neutral) for $C$ in the Equations (6) to (9), this gives $T_{i}=24.8^{\circ} \mathrm{C}$ or $T_{g}=24.4{ }^{\circ} \mathrm{C}$ in the FR mode and $T_{i}=25.5{ }^{\circ} \mathrm{C}$ or $T_{g}=25.6{ }^{\circ} \mathrm{C}$ in the CL mode.

The presence of behavioral adaptation in the data renders the evaluation of comfort temperatures suspect, tending to artificially lower the regression coefficients and therefore the estimates of the comfort temperature. There is therefore a problem in applying the regression method in the presence of adaptive behavior, as has been found in previous research [2,7]. So to avoid this problem the comfort temperatures have been re-estimated using the Griffiths method (in the next section).3.4.2. Griffiths Method

Griffiths [22] suggested a way in which the comfort temperature can be calculated from a small sample of data. Griffiths made the assumption that the increase in temperature for each scale point on the thermal sensation scale was effectively $3{ }^{\circ} \mathrm{C}$ for a seven point scale [23]. This means that for each thermal sensation vote away from neutral, he subtracted or added $3{ }^{\circ} \mathrm{C}$ from the actual temperature at the time to obtain the temperature that might be expected to result in neutrality [23]. The detail of the Griffiths method can be found in the various publications [9,23,24]. The comfort temperature is predicted by the Griffiths' method which is given below.

$$
T_{c}=T+(4-\mathrm{C}) / a
$$

where $T_{c}$ is the comfort temperature by Griffiths' method $\left({ }^{\circ} \mathrm{C}\right), T$ is the indoor air temperature $\left({ }^{\circ} \mathrm{C}\right)$ or globe temperature $\left({ }^{\circ} \mathrm{C}\right)$ and $a$ is the regression coefficient.

In applying the Griffiths' method, Nicol et al. [9] and Humphreys et al. [25] used the constants 0.25, 0.33 and 0.50 for a 7 point thermal sensation scale. We have also investigated the comfort temperature using these regression coefficients. The mean comfort temperature with each coefficient is not very different (Table 8), so it matters little which coefficient is adopted. The comfort temperature calculated using a coefficient of 0.50 is used for further analysis.

Table 8. Comfort temperature predicted by Griffiths' method.

\begin{tabular}{cccccccc}
\hline \multirow{2}{*}{ Mode } & \multirow{2}{*}{ RC } & \multicolumn{3}{c}{$\boldsymbol{T}_{\boldsymbol{c i}}\left({ }^{\circ} \mathbf{C}\right)$} & \multicolumn{3}{c}{$\boldsymbol{T}_{\boldsymbol{c g}}\left({ }^{\circ} \mathbf{C}\right)$} \\
\cline { 3 - 8 } & & $\boldsymbol{N}$ & Mean & S.D. & $\boldsymbol{N}$ & Mean & S.D. \\
\hline \multirow{3}{*}{ FR } & 0.25 & 8282 & 25.7 & 3.1 & 2788 & 25.7 & 3.0 \\
& 0.33 & 8282 & 26.3 & 2.5 & 2788 & 26.2 & 2.5 \\
& 0.50 & 8282 & 27.0 & 2.1 & 2788 & 26.8 & 2.1 \\
\hline \multirow{4}{*}{ CL } & 0.25 & 4857 & 26.7 & 2.9 & 2109 & 26.7 & 2.7 \\
& 0.33 & 4857 & 26.9 & 2.4 & 2109 & 27.0 & 2.2 \\
& 0.50 & 4857 & 27.1 & 2.0 & 2109 & 27.2 & 1.8 \\
\hline
\end{tabular}

Note: RC: regression coefficient; $T_{c i}$ : comfort indoor air temperature; $T_{c g}$ : comfort globe temperature; $N$ : number of sample; S.D.: standard deviation.

The mean comfort indoor air or globe temperature by the Griffiths' method is $27.0^{\circ} \mathrm{C}$ or $26.8^{\circ} \mathrm{C}$ in FR mode and $27.1^{\circ} \mathrm{C}$ or $27.2^{\circ} \mathrm{C}$ in CL mode (Figure 6). The use of the Griffiths method brings together the neutral (comfort) temperatures for the air temperature and the globe temperature, again suggesting that it is more valid than the simple regression model.

Table 9 shows a comparison of the comfort temperature obtained in this study with existing research. The comfort temperature of the existing research is similar to this research. 
(a) Season: Summer

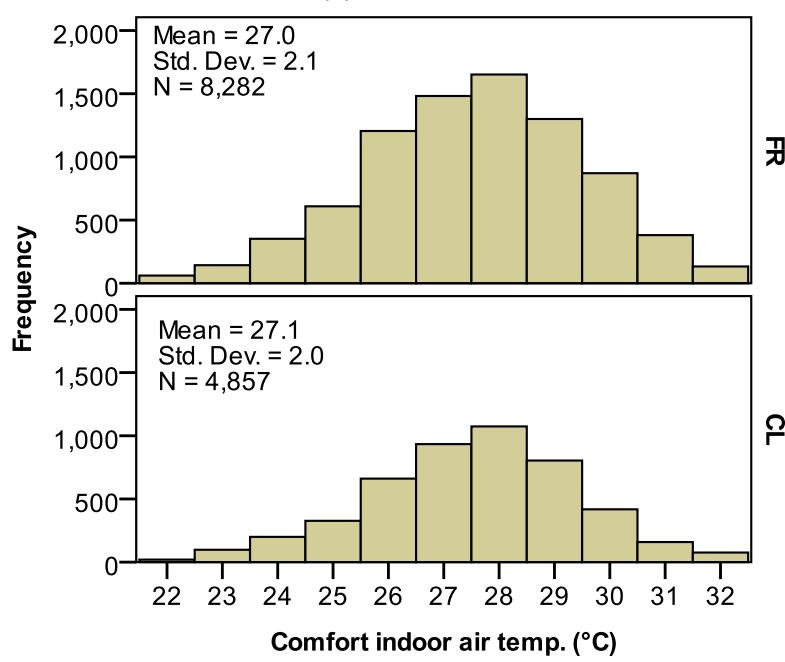

(b) Season: Summer

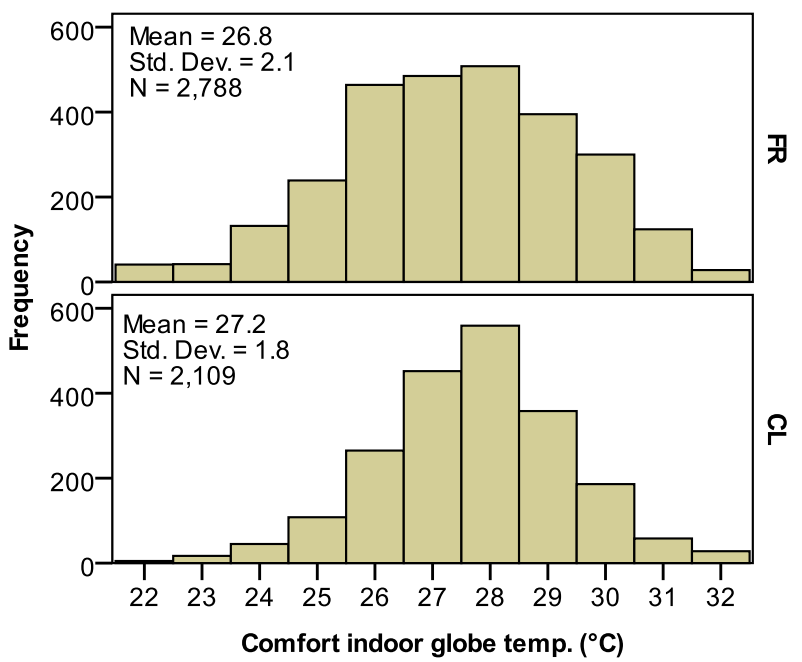

Figure 6. Comfort temperature predicted by Griffiths method: (a) Comfort indoor air temperature; (b) Comfort globe temperature.

Table 9. Comparison of comfort temperature in summer with existing research.

\begin{tabular}{cccc}
\hline Area & References & $\begin{array}{c}\text { Tempeature for } \\
\boldsymbol{T}_{\boldsymbol{c}}\left({ }^{\circ} \mathbf{C}\right)\end{array}$ & $\begin{array}{c}\text { Comfort Tempeature } \\
\boldsymbol{T}_{\boldsymbol{c}}\left({ }^{\circ} \mathbf{C}\right)\end{array}$ \\
\hline Japan (Kanto) & This study (FR mode) & $T_{g}$ & 26.8 \\
Japan (Gifu) & Rijal et al. $[2]$ & $T_{i}$ & 26.1 \\
Japan (Kansai) & Nakaya et al. [1] & $T_{o p}$ & 27.6 \\
China & Han et al. $[3]$ & $T_{o p}$ & 28.6 \\
Singapore & de Dear et al. [4] & $T_{o p}$ & 28.5 \\
Malaysia & Djamila et al. $[5]$ & $T_{i}$ & 30.1 \\
Indonesia & Fedriadi and Wong [6] & $T_{o p}$ & 29.2 \\
Nepal & Rijal et al. $[7]$ & $T_{g}$ & $21.1-30.0$ \\
India & Indraganti [8] & $T_{g}$ & 29.2 \\
Pakistan & Nicol and Roaf [10] & $T_{g}$ & $26.7-29.9$ \\
Iran & Heidari \& Sharples [11] & $T_{i}$ & 28.4 \\
UK & Rijal and Stevenson [12] & $T_{i}$ & 22.9 \\
\hline
\end{tabular}

Note: $T_{g}$ : globe temperature. $\left({ }^{\circ} \mathrm{C}\right), T_{i}$ : indoor air temperature. $\left({ }^{\circ} \mathrm{C}\right), T_{o p}$ : operative temperature. $\left({ }^{\circ} \mathrm{C}\right)$.

\subsection{Comfort Temperature and Humidity}

The humidity is important in the hottest season. In a moist environment, it has been observed that people become uncomfortable with a smaller change in temperature than they do in a dry environment [15]. To explore a possible effect of humidity, the comfort temperature is analyzed by relating it to the relative humidity, absolute humidity and skin moisture. The comfort temperatures were correlated with the indoor relative humidity, absolute humidity and skin moisture sensation (Table 10). However, the correlation effect of the comfort temperature and relative humidity might have simply been attributable to the correlation between air temperature and relative humidity. So to further investigate the effect of humidity on the comfort temperature, multiple regression analysis was conducted for the FR mode.

$$
T_{c i}=0.623 T_{i}-0.006 R H_{i}+9.8
$$




$$
\begin{gathered}
\left(n=8282, R^{2}=0.47, \text { S.E } .1=0.007, \text { S.E } .2=0.002, p_{1}<0.001, p_{2}=0.001\right) \\
T_{c i}=0.656 T_{i}-0.039 A H_{i}+9.0 \\
\left(n=8282, R^{2}=0.47, \text { S.E. } 1=0.010, \text { S.E } .2=0.008, p_{1} \text { and } p_{2}<0.001\right) \\
T_{c i}=0.825 T_{i}-1.317 S M+5.8 \\
\left(n=7868, R^{2}=0.68, \text { S.E. } 1=0.006, \text { S.E. } 2=0.019, p_{1} \text { and } p_{2}<0.001\right) .
\end{gathered}
$$

where $T_{c i}$ : Comfort indoor air temperature $\left({ }^{\circ} \mathrm{C}\right) ; R H_{i}$ : Indoor relative humidity (\%); $A H_{i}$ : Indoor absolute humidity (g/kg (Dry Air)); SM: Skin moisture sensation; S.E.1 and S.E.2: Standard Error of regression coefficient for first and second terms; $p_{1}$ and $p_{2}$ : Significance level of the regression coefficients of the first and second terms.

As may be seen from the equations, neither the relative humidity nor the absolute humidity had, in these data, an important effect on the comfort temperature. However, Nicol [15] found that in a humid climate or in conditions when the relative humidity is high people may require temperatures that are about $1{ }^{\circ} \mathrm{C}$ lower to remain comfortable. As for the skin moisture, Equation (13) shows it has a considerable effect on the comfort temperature, an increase of one category in the level of skin moisture reducing the comfort temperature by approximately $1.3 \mathrm{~K}$ (Figure 7 ).

Table 10. Correlation coefficient in FR mode.

\begin{tabular}{ccccccc}
\hline Items & $\boldsymbol{T}_{\mathrm{c} i}: \boldsymbol{R H}_{\boldsymbol{i}}$ & $\boldsymbol{T}_{\mathrm{cg}}: \boldsymbol{R H}_{\boldsymbol{i}}$ & $\boldsymbol{T}_{\mathrm{c} i:} \boldsymbol{A} \boldsymbol{H}_{\boldsymbol{i}}$ & $\boldsymbol{T}_{\mathrm{cg}: \boldsymbol{A} \boldsymbol{H}_{\boldsymbol{i}}}$ & $\boldsymbol{T}_{\mathrm{c} \boldsymbol{i}:}: \boldsymbol{S M}$ & $\boldsymbol{T}_{\mathrm{cg}}: \boldsymbol{S M}$ \\
\hline$r$ & -0.10 & -0.15 & 0.42 & 0.38 & -0.11 & -0.06 \\
$p$ & $<0.001$ & $<0.001$ & $<0.001$ & $<0.001$ & $<0.001$ & 0.003 \\
$N$ & 8282 & 2750 & 8282 & 2750 & 7868 & 2786 \\
\hline
\end{tabular}

Note: $r$ : Correlation coefficient; $\mathrm{p}$ : Significance level; $N$ : Number of sample; $T_{\mathrm{c} i}$ : Comfort indoor temperature $\left({ }^{\circ} \mathrm{C}\right)$; $T_{\mathrm{cg}}$ : Comfort globe temperature $\left({ }^{\circ} \mathrm{C}\right) ; R H_{i}$ : Indoor relative humidity (\%); $A H_{i}$ : Indoor absolute humidity (g/kg(Dry Air)); SM: Skin moisture sensation.

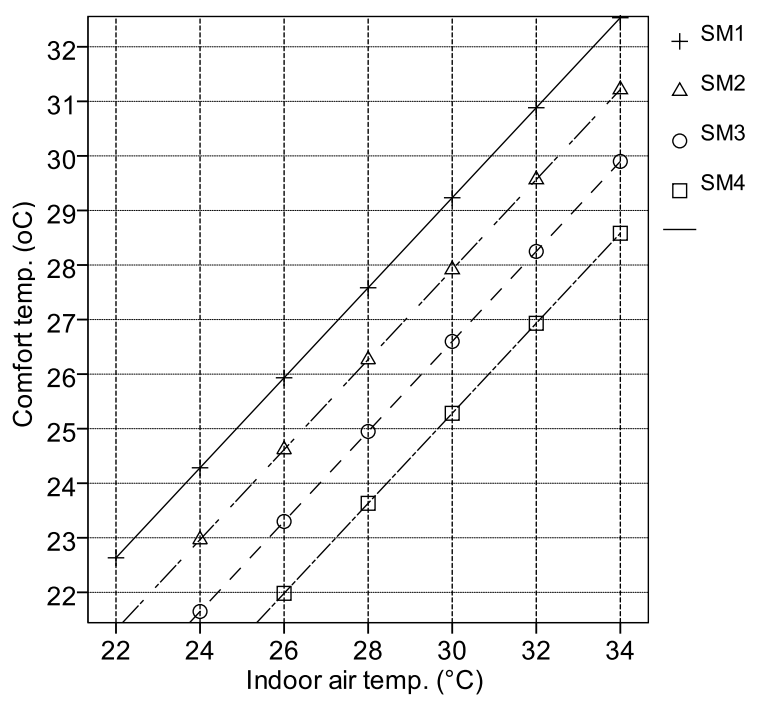

Figure 7. Relation between the comfort temperature and the indoor air temperature for the four levels of skin moisture. 
Nicol [26] found that when indoor air temperature is $31-40{ }^{\circ} \mathrm{C}$, increased air speed reduced the assessed skin moisture. Our results therefore imply that the evaporation of the skin moisture is important in raising the comfort temperature in Japan's hot and humid season.

\subsection{A Comparison with the Adaptive Model}

It is well known that people adapt to the temperature of their accommodation, and thus comfort temperature has corresponding seasonal and regional differences in relation to the outdoor temperature [20]. To predict such indoor comfort temperatures, the $\mathrm{CEN}$ and Chartered Institution of Building Services Engineers (CIBSE) proposed an adaptive model for office buildings. We compare our results with these adaptive models.

The running mean outdoor temperature $\left(T_{r m}\right)$ is used in the adaptive model. It is the exponentially weighted daily mean outdoor temperature. It is calculated using the following equation [14,23,27,28].

$$
T_{r m}=\alpha T_{r m-1}+(1-\alpha) T_{o d-1}
$$

where $T_{r m-1}$ is the running mean outdoor temperature for the previous day $\left({ }^{\circ} \mathrm{C}\right), T_{o d-1}$ is the daily mean outdoor temperature for the previous day $\left({ }^{\circ} \mathrm{C}\right.$ ). So, if the running mean has been calculated (or assumed) for one day, then it can be readily calculated for the next day, and so on. $\alpha$ is a constant between the 0 and 1 which defines the speed at which the running mean responds to the outdoor air temperature. In this research $\alpha$ is assumed to be 0.8 , a value previously found to be appropriate.

Figure 8 shows the relation between the comfort temperature and the running mean outdoor temperature. The six parallel lines in Figure 8a show the acceptable zone of the adaptive model of CEN standard [14]. The two parallel lines in Figure 8b show upper and lower margins of the comfort temperature [28]. The Japanese guide line is also shown in the figure.

Generally the comfort temperature of FR mode is within the acceptable zone of the adaptive model. As for the CL mode, the comfort temperature is higher than the CIBSE guide [28] and Japanese guide line. The results showed that the residents are adapting to the higher indoor air temperature of the houses.
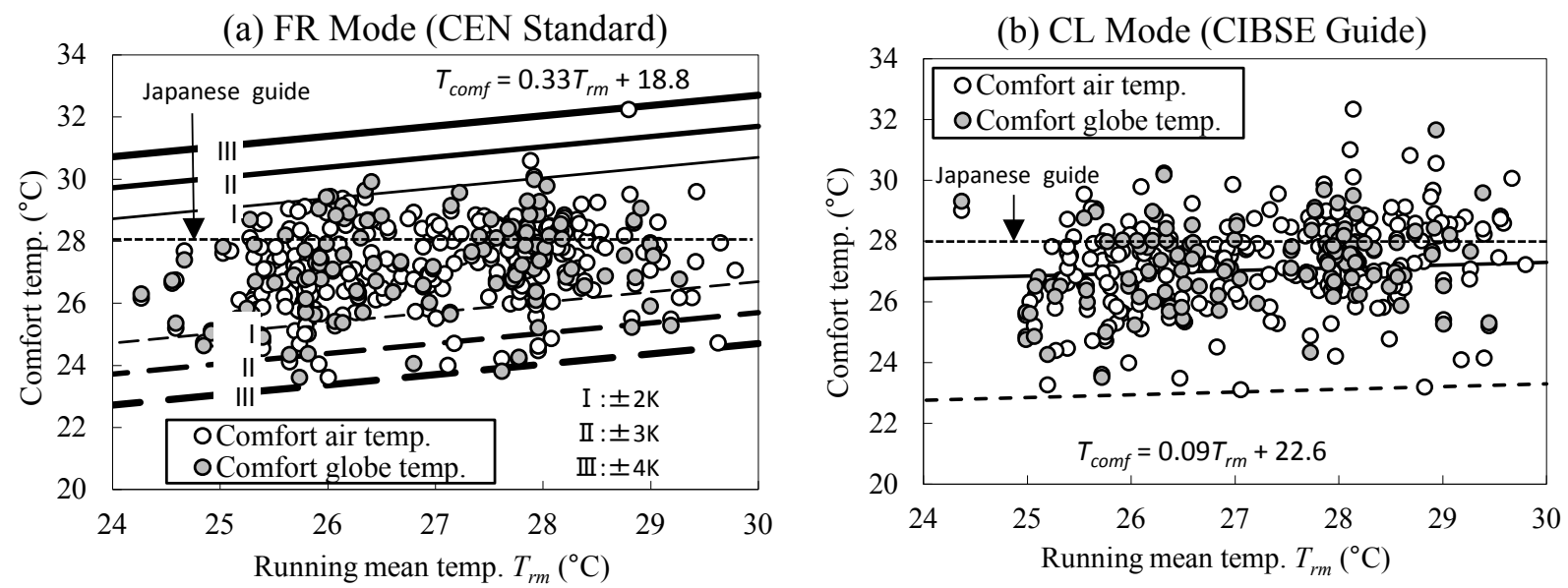

Figure 8. Comparison with the adaptive model: (a) FR mode (CEN standard); (b) CL mode (CIBSE guide). Each point represents the monthly mean comfort temperature of each subject. 


\subsection{Occupant Behaviour}

As we have shown in the previous sections, the residents questioned are adapting in summertime to higher indoor air temperature of the houses. Residents might be regulating their thermal comfort by using various adaptations: behavioral, physiological and psychological [29]. This section focuses on behavioral adaptation. Nicol and Humphreys [30] made use of logistic regression analysis to predict occupant control behavior in naturally ventilated buildings. We have also adopted the logistic regression method to predict the window opening and fan use in the living room. The relationship between the probability of windows being open or a fan in use $(p)$ and the indoor or outdoor temperature $(T)$ is of the form:

$$
\begin{gathered}
\operatorname{logit}(p)=\log [p /(1-p)]=b T+c \\
p=\exp ^{(b T+c) /\left[1+\exp ^{(b T+c)}\right]}
\end{gathered}
$$

where $\exp$ (exponential function) is the base of natural logarithm, $b$ is the regression coefficient for $T$, and $c$ is the constant in the regression equation.

The following regression equations were obtained in between the window opening or fan use and temperatures for FR mode.

Window opening:

$$
\begin{aligned}
& \operatorname{logit}(p)=0.246 T_{i}-6.1\left(n=8216, R^{2}=0.06, \text { S.E. }=0.011, p<0.001\right) \\
& \operatorname{logit}(p)=0.199 T_{g}-4.6\left(n=2771, R^{2}=0.04, \text { S.E. }=0.019, p<0.001\right) \\
& \operatorname{logit}(p)=0.146 T_{o}-3.0\left(n=8254, R^{2}=0.05, \text { S.E. }=0.007, p<0.001\right)
\end{aligned}
$$

Fan use:

$$
\begin{gathered}
\operatorname{logit}(p)=0.319 T_{i}-9.7\left(n=7961, R^{2}=0.09, \text { S.E. }=0.013, p<0.001\right) \\
\operatorname{logit}(p)=0.421 T_{g}-12.5\left(n=2749, R^{2}=0.15, \text { S.E. }=0.023, p<0.001\right) \\
\operatorname{logit}(p)=0.166 T_{o}-5.0\left(n=7993, R^{2}=0.06, \text { S.E. }=0.008, p<0.001\right)
\end{gathered}
$$

where $T_{i}$ is indoor air temperature $\left({ }^{\circ} \mathrm{C}\right), T_{g}$ is indoor globe temperature $\left({ }^{\circ} \mathrm{C}\right), T_{o}$ is outdoor air temperature $\left({ }^{\circ} \mathrm{C}\right)$ and $R^{2}$ is Cox and Snell $R^{2}$.

Even though the coefficient of determination is low, the equations are statistically significant. These equations are shown in Figure 9. The predicted proportion of window opening or fan use is well matched with the measured values, as can be seen from the figure (the points shown are the proportions for the data in groups of width $1 \mathrm{~K}$ ). The proportion of window opening or fan use is increased when temperature rises. The window opening behavior is similar to that found in previous research [2,24].

The regression coefficient for indoor air temperature or globe temperature is higher than the outdoor air temperature. It seems that the occupants respond more closely to the indoor temperatures than outdoor air temperature while operating the windows and fans.

Window opening and fan use might be important to increase the air movement and modify the indoor air temperature. Window opening is effective at increasing the indoor comfort temperature [2,31]. Theoretically, if wind velocity is $1 \mathrm{~m} / \mathrm{s}$, the indoor comfort temperature can be increased by some 3 or $4{ }^{\circ} \mathrm{C}[15,32,33]$. Nicol [15] found that the presence of air movement can be equivalent to a reduction in 
indoor temperature of as much as $4{ }^{\circ} \mathrm{C}$. When outdoor running mean temperature is $30^{\circ} \mathrm{C}$, the indoor comfort temperature when the fan is on is $31^{\circ} \mathrm{C}$ which is $2.2{ }^{\circ} \mathrm{C}$ higher than when the fan is off $[24,33]$.

Thus, the results showed that residents undertake behavioral adaptation to regulate their hot and humid thermal environment.
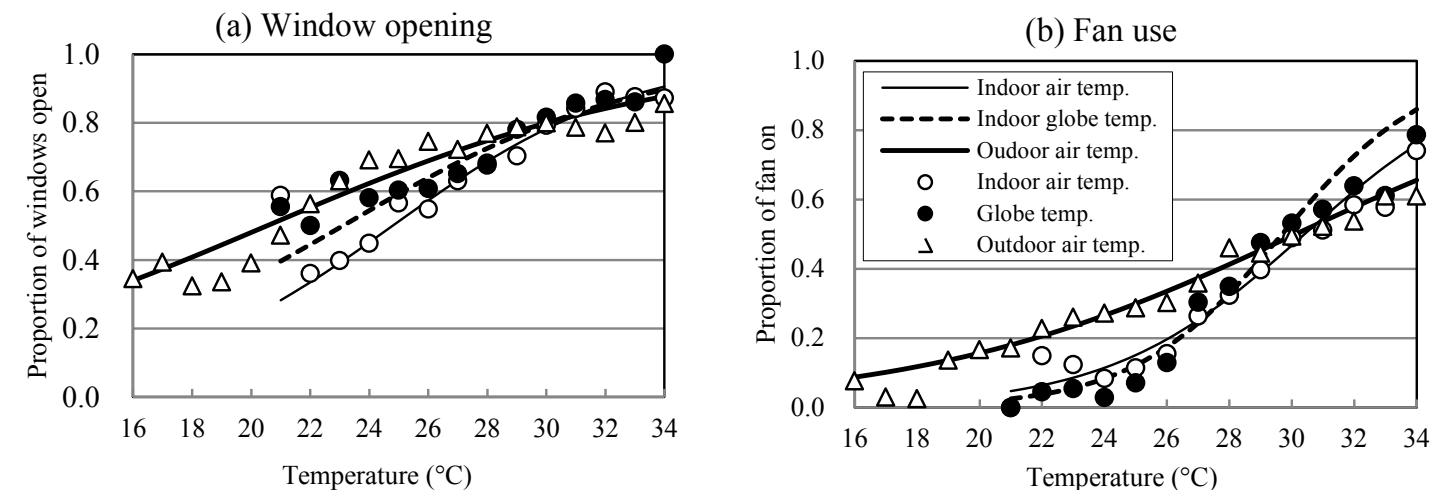

Figure 9. Relation between the use of controls and temperature: (a) Window opening; (b) Fan use. Measured values were grouped for every $1{ }^{\circ} \mathrm{C}$ for temperatures. The grouped data for samples less than 10 are not shown.

\section{Conclusions}

In order to explore the variation of the comfort temperature, and to investigate the behavioral adaptation in Japanese houses, we conducted a thermal comfort and occupant behavior survey in 120 houses in living-rooms and bedrooms for the hot and humid season in the Kanto region of Japan. The chief findings were as follows:

1. The proportion of people in thermal comfort was $83 \%$ in FR mode, showing that the residents were generally well-adapted and satisfied with the thermal environment in their houses.

2. The mean comfort temperature in free running mode was $27.0^{\circ} \mathrm{C}$ in hot and humid season. The comfort temperature obtained in this study is within the acceptable zone of the CEN adaptive model.

3. The comfort temperature was related to the skin moisture sensation, and thus the evaporation of the skin moisture raises the comfort temperature in the hot and humid season.

4. The residents adapted to hot and humid environments by increasing the air movement usage through actions such as opening the windows and using fans. The design of the openable window and ceiling fan are important for the success of adaptive thermal comfort in a hot and humid climate.

The results show what room temperatures were prevalent in this large sample of Japanese dwellings during the summer. That the residents were largely happy with these conditions indicates that the dwellings were of suitable design for the climate and culture. It is of course unwise to generalize from these results to dwellings worldwide. However, that our results are similar to those found from surveys in dwellings in other countries with hot and humid summers, and that our results are consistent with those portrayed by the European adaptive standard, suggest a wider range of applicability. 


\section{Acknowledgments}

We would like to thank the households who participated in the survey and the students for data entry. This research was supported by Grant-in-Aid for Scientific Research (C) Number 24560726.

\section{Author Contributions}

The different expertise of each author of this paper has contributed substantially to its development. Hom B. Rijal collected and analyzed the data and drafted the paper. Michael Humphreys and Fergus Nicol helped with the analysis, and reviewed and edited the paper.

\section{Conflicts of Interest}

The authors declare no conflict of interest.

\section{References}

1. Nakaya, T.; Matsubara, N.; Kurazumi, Y. A field study of thermal environment and thermal comfort in Kansai region, Japan: Neutral temperature and acceptable range in summer. J. Environ. Eng. AIJ 2005, 597, 51-56.

2. Rijal, H.B.; Honjo, M.; Kobayashi, R.; Nakaya, T. Investigation of comfort temperature, adaptive model and the window opening behaviour in Japanese houses. Archit. Sci. Rev. 2013, 56, 54-69.

3. Han, J.; Zhang, G.; Zhang, Q.; Zhang, J.; Liu, J.; Tian, L.; Zheng, C.; Hao, J.; Lin, J.; Liu, Y.; et al. Field study on occupants' thermal comfort and residential thermal environment in a hot-humid climate of China. Build. Environ. 2007, 42, 4043-4050.

4. De Dear, R.J.; Leow, K.G.; Foo, S.C. Thermal comfort in the humid tropics: Field experiments in air-conditioned and naturally ventilated buildings in Singapore. Int. J. Biometeorol. 1991, 34, 259-265.

5. Djamila, H.; Chu, C.M.; Kumaresan, S. Field study of thermal comfort in residential buildings in the equatorial hot-humid climate of Malaysia. Build. Environ. 2013, 62, 133-142.

6. Feriadi, H.; Wong, N.H. Thermal comfort for naturally ventilated houses in Indonesia. Energy Build. 2004, 36, 614-626.

7. Rijal, H.B.; Yoshida, H.; Umemiya, N. Seasonal and regional differences in neutral temperatures in Nepalese traditional vernacular houses. Build. Environ. 2010, 45, 2743-2753.

8. Indraganti, M.; Using the adaptive model of thermal comfort for obtaining the indoor neutral temperature: Findings form a field study in Hyderabad. Build. Environ. 2010, 45, 519-536.

9. Nicol, F.; Jamy, G.N.; Sykes, O.; Humphreys, M.; Roaf, S.; Hancock, M. A Survey of Thermal Comfort in Pakistan toward New Indoor Temperature Standards; Oxford Brookes University: Oxford, UK, 1994.

10. Nicol, F.; Roaf, S. Pioneering new indoor temperature standards: The Pakistan project. Energy Build. 1996, 23, 169-174.

11. Heidari, S.; Sharples, S. A comparative analysis of short-term and long-term thermal comfort surveys in Iran. Energy Build. 2002, 34, 607-614. 
12. Rijal, H.B.; Stevenson, F. Thermal Comfort in UK Housing to Avoid Overheating: Lessons from a "Zero Carbon" Case Study. In Proceedings of the Conference Adapting to Change: New Thinking on Comfort, Windsor, UK, 9-11 April 2010.

13. American Society of Heating Refrigeration and Air-Conditioning Engineers (AHRAE). Thermal Environment Conditions for Human Occupancy; American Society of Heating Refrigeration and Air-Conditioning Engineers: Atlanta, GA, USA, 2004.

14. Comité Européen de Normalisation (CEN). Indoor Environmental Input Parameters for Design and Assessment of Energy Performance of Buildings Addressing Indoor Air Quality, Thermal Environment, Lighting and Acoustics; EN 15251; Comité Européen de Normalisation (CEN): Brussels, Belgium, 2007.

15. Nicol, F. Adaptive thermal comfort standards in the hot-humid tropics. Energy Build. 2004, 36, 628-637.

16. Rijal, H.B. Investigation of comfort temperature and occupant behavior in Japanese houses during the hot and humid season. Buildings 2014, 4, 437-452.

17. Rijal, H.B.; Humphreys, M.A.; Nicol, J.F. Effect of Humidity on the Comfort Temperature in Japanese Houses during the Summer Season. In Proceedings of 2015 TAU Conference: Mitigating and Adapting Built Environments for Climate Change in the Tropics, Jakarta, Indonesia, 30-31 March 2015.

18. Rijal, H.B.; Humphreys, M.A.; Nicol, J.F. Development of The Adaptive Model for Thermal Comfort in Japanese Houses. In Proceedings of 8th Windsor Conference: Counting the Cost of Comfort in a Changing World, Cumberland Lodge, Windsor, UK, 10-13 April 2014.

19. McIntyre, D.A. Indoor Climate; Applied Science Publishers: London, UK, 1980.

20. Humphreys, M.A. Outdoor temperatures and comfort indoors. Build. Res. Pract. 1978, 6, 92-105.

21. Finney, D.J. Probit Analysis; Cambridge University Press: Cambridge, UK, 1971.

22. Griffiths, I.D. Thermal Comfort in Buildings with Passive Solar Features: Field Studies, Report to the Commission of the European Communities; University of Surrey Guildford: Surrey, UK, 1990.

23. Nicol, F.; Humphreys, M.; Roaf, S. Adaptive Thermal Comfort: Principles and Practice; Earthscan: London, UK, 2012.

24. Rijal, H.B.; Tuohy, P.; Humphreys, M.A.; Nicol, J.F.; Samuel, A.; Raja, I.A.; Clarke, J. Development of adaptive algorithms for the operation of windows, fans and doors to predict thermal comfort and energy use in Pakistani buildings. ASHRAE Trans. 2008, 114, 555-573.

25. Humphreys, M.A.; Rijal, H.B.; Nicol, J.F. Updating the adaptive relation between climate and comfort indoors; new insights and an extended database. Build. Environ. 2013, 63, 40-55.

26. Nicol, J.F. An analysis of some observations of thermal comfort in Roorkee, India and Baghdad, Iraq. Ann. Hum. Biol. 1974, 1, 411-426.

27. McCartney, K.J.; Nicol, J.F. Developing an adaptive control algorithm for Europe. Energy Build. 2002, 34, 623-635.

28. Humphreys, M.A.; Nicol, J.F. Environmental Criteria for Design. In Environmental Design: CIBSE Guide A; Chartered Institution of Building Services Engineers (CIBSE): London, UK, 2006.

29. Brager, G.; de Dear, R. Thermal adaptation in the built environment: A literature review. Energy Build. 1998, 27, 83-96. 
30. Nicol, J.F.; Humphreys, M.A. A stochastic approach to thermal comfort-Occupant behavior and energy use in buildings. ASHRAE Trans. 2004, 110, 554-568.

31. Brager, G.S.; Paliaga, G.; de Dear, R. Operable windows, personal control, and occupant comfort. ASHRAE Transac. 2004, 110, 17-33.

32. Humphreys, M.A. A simple theoretical derivation of thermal comfort conditions. J. Instit. Heat. Vent. Eng. 1970, 38, 95-98.

33. Rijal, H.B. Thermal Adaptation Outdoors and the Effect of Wind on Thermal Comfort. In Ventilating Cities Air-flow-Criteria for Healthy and Comfortable Urban Living; Kato, S., Hiyama, K., Eds.; Springer: Berlin, Germany, 2012; pp. 33-58.

(C) 2015 by the authors; licensee MDPI, Basel, Switzerland. This article is an open access article distributed under the terms and conditions of the Creative Commons Attribution license (http://creativecommons.org/licenses/by/4.0/). 